\title{
Back Analysis of Rock Hydraulic Fracturing by Coupling Numerical Model and Computational Intelligent Technology
}

\author{
Shaojun Li, ${ }^{1}$ Hongbo Zhao, ${ }^{2}$ Xiating Feng, ${ }^{1}$ Quan Jiang, ${ }^{1}$ and Qiancheng Sun ${ }^{1}$ \\ ${ }^{1}$ State Key Laboratory of Geomechanics and Geotechnical Engineering, Institute of Rock and Soil Mechanics, \\ Chinese Academy of Sciences, Wuhan, Hubei 430071, China \\ ${ }^{2}$ School of Civil Engineering, Henan Polytechnic University, Jiaozuo 454003, China \\ Correspondence should be addressed to Shaojun Li; sjli@whrsm.ac.cn
}

Received 17 June 2017; Revised 23 August 2017; Accepted 7 September 2017; Published 18 October 2017

Academic Editor: Zhongwei Chen

Copyright (c) 2017 Shaojun Li et al. This is an open access article distributed under the Creative Commons Attribution License, which permits unrestricted use, distribution, and reproduction in any medium, provided the original work is properly cited.

\begin{abstract}
Hydraulic fracturing is widely used to determine in situ stress of rock engineering. In this paper we propose a new method for simultaneously determining the in situ stress and elastic parameters of rock. The method utilizing the hydraulic fracturing numerical model and a computational intelligent method is proposed and verified. The hydraulic fracturing numerical model provides the samples which include borehole pressure, in situ stress, and elastic parameters. A computational intelligent method is applied in back analysis. A multioutput support vector machine is used to map the complex, nonlinear relationship between the in situ stress, elastic parameters, and borehole pressure. The artificial bee colony algorithm is applied in back analysis to find the optimal in situ stress and elastic parameters. The in situ stress is determined using the proposed method and the results are compared with those of the classic breakdown formula. The proposed method provides a good estimate of the relationship between the in situ stress and borehole pressure and predicts the maximum horizontal in situ stress with high precision while considering the influence of pore pressure without the need to estimate Biot's coefficient and other parameters.
\end{abstract}

\section{Introduction}

Hydraulic fracturing is widely used in the recovery of oil, gas, geothermal, and mineral resources [1]. In petroleum engineering it is important to determine the in situ stresses and elastic parameters of the rock mass when using hydraulic fracturing in fracturing operations, wellbore stability analysis, and reservoir simulation [2]. While high accuracy is required for the values of the in situ stress and mechanical parameters of the rock mass, determination of these parameters is still one of the most challenging tasks in hydraulic fracturing.

Hydraulic fracturing tests are considered the most effective method for determining the in situ stress and mechanical parameters of rock mass [3-9]. The Hubbert and Willis hydraulic fracturing criterion and Haimson and Fairhurst's hydraulic fracturing criterion are the two classic formulae for hydrofracture breakdown ([10]; Hubbert et al., 1953). However, the pore pressure term, which is a significant factor in deep boreholes, is ignored in Hubbert and Willis's hydraulic fracturing criterion. Modifications of the original equations were proposed to account for the pore pressure (Detournay et al., 1988; [1, 11-13]), but they have not been used in practice because it involves the Biot poroelastic parameters and Poisson's ratio which are difficult to obtain. Schmitt and Zoback built a more useful generalized form of the hydrofracture breakdown equation by considering the poroelastic effects [1]. It can be used to provide upper and lower bound to the maximum horizontal in situ stress because it depends on the specific pore and microcrack structure. However, this method requires the poroelastic coefficients which are difficult to determine in practice.

Owing to the limitations of the classic breakdown formulae and the complexity of hydraulic fracturing tests, laboratory and field tests have been commonly used to determine the in situ stress and mechanical parameters of rock mass (Algorithm 1). However, these tests may not always produce the poroelastic parameters or may provide inaccurate results 
Sub MSVM()

Dim N As Integer ' The number of training samples

Dim Dim_x As Integer ' The dimension of input variables

Dim Dim_y As Integer ' The number of output variables

Dim C As Double ' Pentalty factor of SVM

Dim epsilon As Double

Dim sigma As Double

Dim X_input() As Double ' The input of training samples

Dim Y_output() As Double ' The output of traning samples

\author{
' The one sample \\ Dim xi() As Double \\ Dim xj() As Double \\ "The weights of MSVM \\ Dim W() As Double \\ Dim $b()$ As Double \\ Dim W_k() As Double \\ Dim b_k() As Double \\ Dim W_s() As Double \\ Dim b_s() As Double \\ ' the error of each sample \\ Dim u() As Double \\ Dim ai() As Double \\ Dim ui() As Double \\ Dim u_new() As Double
}

'The coefficient of matrix for computing Ws and bs

$\operatorname{Dim} A()$ As Double

Dim BB() As Double

Dim A_last_row() As Double

Dim B_last_row() As Double

'The Descending direction

Dim P_W() As Double

Dim P_b() As Double

Dim k() As Double

Dim D_a() As Double

Dim D_a_1() As Double

Dim kf() As Double

Dim I As Integer

Dim $\mathrm{j}$ As Integer

Dim 1 As Integer

'The step size eta $\mathrm{k}$

Dim eta As Double

'The control parameters of algorithm convergence

Dim delta_u As Double

Dim $t$ As Integer

Algorithm 1: Continued. 
'The value of the numbers of parameters of training samples

$\mathrm{N}=$ Range("N").Cells.Value

Dim_x = Range("Dim_x").Cells.Value

Dim_y = Range("Dim_y").Cells.Value

'The parameters of SVM

$\mathrm{C}=$ Range("_C").Cells.Value

epsilon = Range("epsilon").Cells.Value

sigma $=$ Range("sigma").Cells.Value

ReDim X_input(1 To N, 1 To Dim_x) As Double ReDim Y_output(1 To N, 1 To Dim_y) As Double

ReDim xi(1 To Dim_x) As Double

ReDim xj(1 To Dim_x) As Double

ReDim W(1 To Dim_y, 1 To N) As Double

ReDim b(1 To Dim_y) As Double

ReDim W_k(1 To Dim_y, 1 To N) As Double

ReDim b_k(1 To Dim_y) As Double

ReDim W_s(1 To Dim_y, 1 To N) As Double

ReDim b_s(1 To Dim_y) As Double

ReDim u(1 To N) As Double

ReDim ai(1 To N) As Double

ReDim ui(1 To Dim_y) As Double

ReDim u_new(1 To N) As Double

ReDim A(1 To N + 1, 1 To $\mathrm{N}+1)$ As Double

'ReDim X(1 To N + 1, 1 To Dim_y) As Double

ReDim BB(1 To N + 1, 1 To Dim_y) As Double

ReDim A_last_row(1 To N) As Double

ReDim B_last_row(1 To Dim_y) As Double

ReDim P_W(1 To Dim_y, 1 To N) As Double

ReDim P_b(1 To Dim_y) As Double

ReDim k(1 To N, 1 To N) As Double

ReDim D_a(1 To N, 1 To N) As Double

ReDim D_a_1(1 To N, 1 To N) As Double

ReDim kf(1 To N) As Double

'Read the input of training samples

For $\mathrm{I}=1$ To $\mathrm{N}$

For $\mathrm{j}=1$ To Dim_x

X_input $(I, j)=$ Range("xi").Cells $(I, j)$

$$
\text { Next }
$$

Next

'Read the output of training samples

For $\mathrm{I}=1$ To $\mathrm{N}$

$$
\text { For } \mathrm{j}=1 \text { To Dim_y }
$$

Y_output $(I, j)=$ Range("yi").Cells(I, j).Value

Next

Next

' The initial value of $\mathrm{Wk}$ and $\mathrm{bk}$

For $\mathrm{I}=1$ To Dim_y

$\mathrm{b}(\mathrm{I})=0$

For $\mathrm{j}=1$ To $\mathrm{N}$

$\mathrm{W}(\mathrm{I}, \mathrm{j})=0$

Next

Next

delta_u $=1$ 
$t=0$

'The iteration process of algorithm

While (delta_u $>0.001$ And $\mathrm{t}<100$ )

' Replace the value of Wk and bk by the New w and b

For $\mathrm{I}=1$ To Dim_y

For $\mathrm{j}=1$ To $\mathrm{N}$

$\mathrm{W} \_\mathrm{k}(\mathrm{I}, \mathrm{j})=\mathrm{W}(\mathrm{I}, \mathrm{j})$

Next

$\mathrm{b} \_\mathrm{k}(\mathrm{I})=\mathrm{b}(\mathrm{I})$

Next

' Compute the value of ui and ai

For $\mathrm{I}=1$ To $\mathrm{N}$

$\mathrm{u}(\mathrm{I})=0$

For $\mathrm{j}=1$ To $\operatorname{Dim} \_\mathrm{x}$

$x i(j)=X \_i n p u t(I, j)$

Next

For $\mathrm{ii}=1$ To $\mathrm{N}$

For $\mathrm{j}=1$ To Dim_x

$x j(j)=X \_$input $(i i, j)$

Next

$\mathrm{kf}(\mathrm{ii})=$ kernel_fun( $\mathrm{xi}, \mathrm{xj}$, sigma $)$

Next

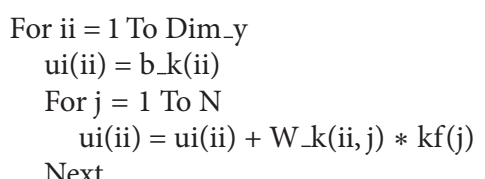

Next

For $j=1$ To Dim_y

$\mathrm{u}(\mathrm{I})=\mathrm{u}(\mathrm{I})+(\text { Y_output }(\mathrm{I}, \mathrm{j})-\mathrm{ui}(\mathrm{j}))^{\wedge} 2$

Next

$\mathrm{u}(\mathrm{I})=\operatorname{Sqr}(\mathrm{u}(\mathrm{I}))$

If $(\mathrm{u}(\mathrm{I})<$ epsilon $)$ Then ai $(\mathrm{I})=0$

If $(\mathrm{u}(\mathrm{I})>=$ epsilon) Then $\mathrm{ai}(\mathrm{I})=2 * \mathrm{C} *(\mathrm{u}(\mathrm{I})-$ epsilon $) / \mathrm{u}(\mathrm{I})$

Next

ai(i) $=2 * \mathrm{C} *(\mathrm{u}(\mathrm{i})-$ epsilon $) / \mathrm{u}(\mathrm{i})$

'compute the Matrix $\mathrm{K}$ and $\mathrm{Da}$

For $\mathrm{I}=1$ To $\mathrm{N}$

For $\mathrm{j}=1$ To N

For $1=1$ To Dim $\_x$

$\mathrm{xi}(\mathrm{l})=\mathrm{X}$ input $(\mathrm{I}, \mathrm{l})$

$\operatorname{xj}(1)=X \_$input $(j, 1)$

Next

$k(I, j)=$ kernel_fun( $x i, x j$, sigma $)$

If $(I=j)$ Then D_a(I, j) = ai(I) Else D_a $(I, j)=0$

Next

Next

For $\mathrm{I}=1$ To $\mathrm{N}$

For $\mathrm{j}=1$ To $\mathrm{N}$

If $(I=j)$ Then $A(I, j)=k(I, j)+1 / D \_a(I, j)$ Else A(I,j) $=k(I, j)$

Algorithm 1: Continued. 


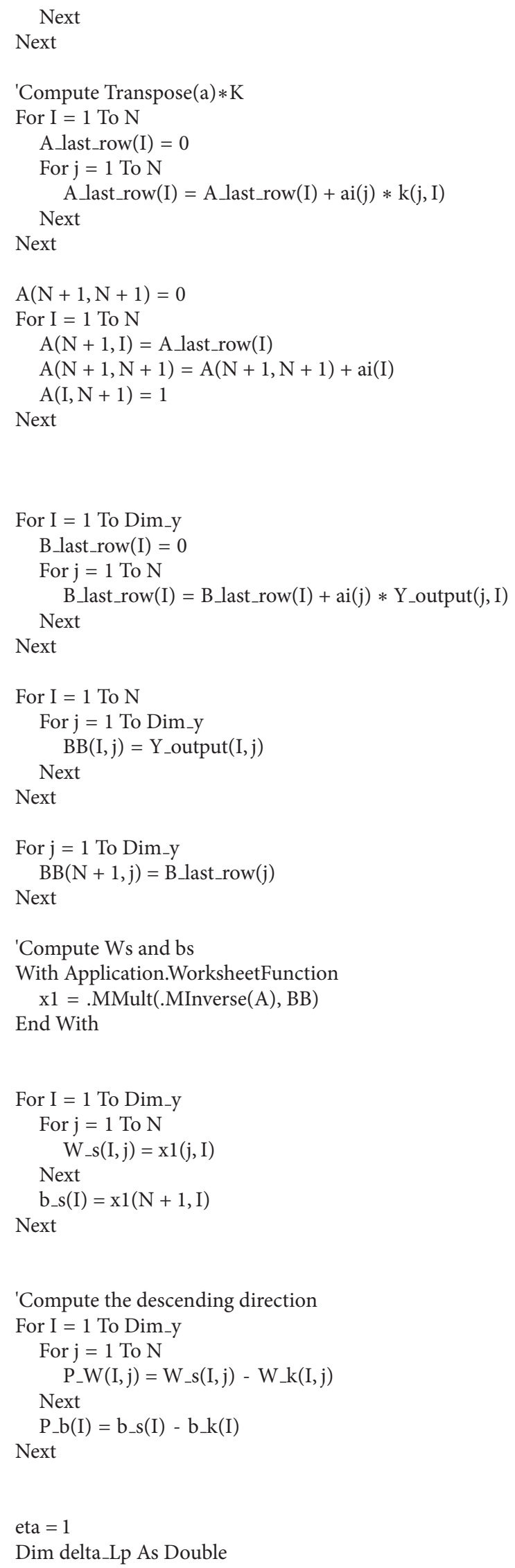


Dim Lp_k_1 As Double

Dim Lp_k As Double

delta_Lp $=1$

'Update the solution of $\mathrm{W}$ and $\mathrm{b}$

While (delta_Lp > 0.0001)

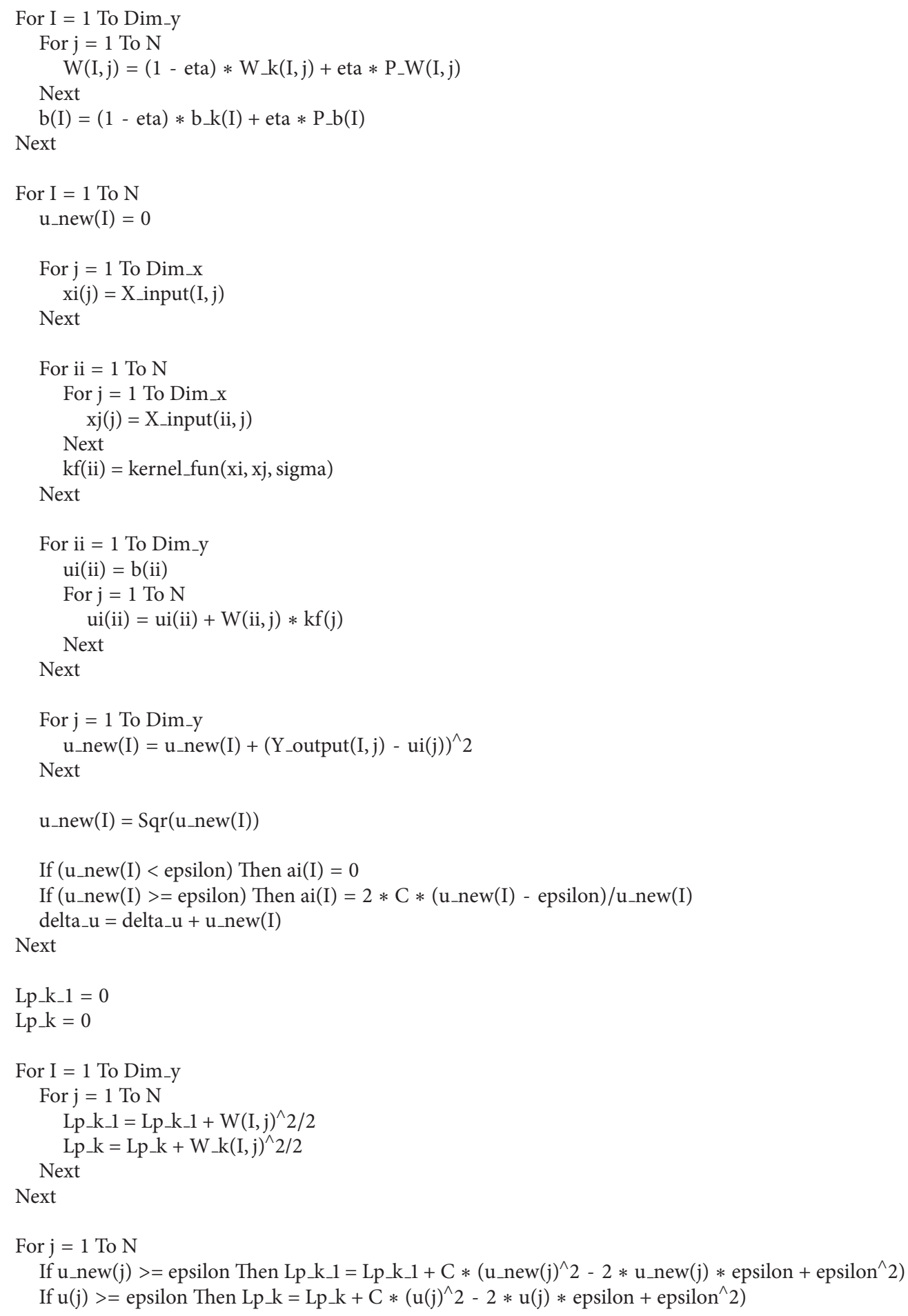




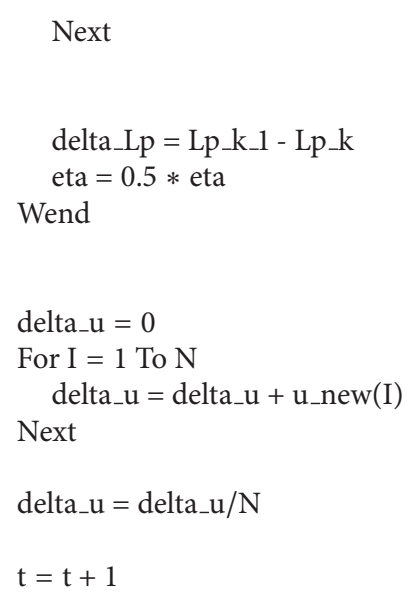

Wend

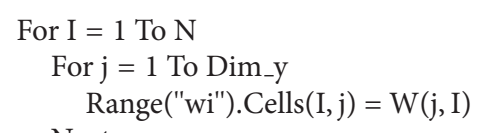


Dim xj() As Double

Dim W() As Double

Dim b() As Double

Dim Yy_p() As Double

Dim $\operatorname{kf}()$ As Double

$\mathrm{N}=$ Range("N").Cells.Value

$\mathrm{Np}=$ Range("Np").Cells.Value

Dim_x = Range("Dim_x").Cells.Value

Dim_y = Range("Dim_y").Cells.Value

sigma $=$ Range("sigma").Cells.Value

ReDim xi(1 To Dim_x) As Double

ReDim xj(1 To Dim_x) As Double

ReDim W(1 To Dim_y, 1 To N) As Double

ReDim b(1 To Dim_y) As Double

ReDim Yy_p(1 To Np, 1 To Dim_y) As Double

ReDim kf(1 To N) As Double

For $\mathrm{I}=1$ To Dim_y

For $\mathrm{j}=1$ To $\mathrm{N}$

$W(I, j)=$ Range("wi").Cells(j, I)

Next

Next

b(I) = Range("bi").Cells(I)

For $\mathrm{I}=1$ To $\mathrm{Np}$

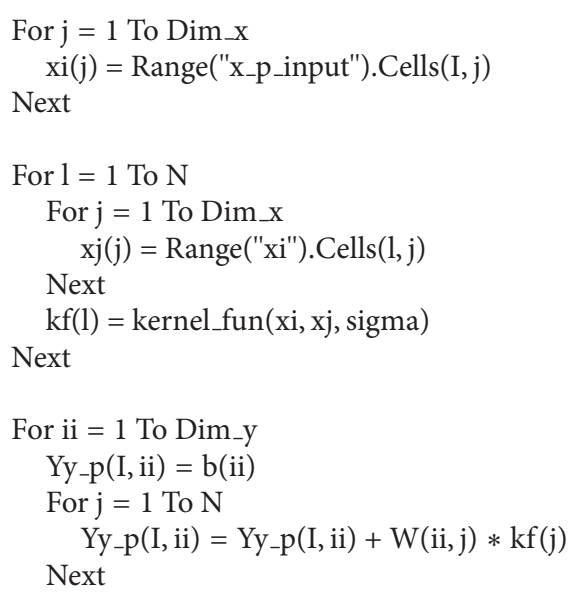

Next

Next

For I = 1 To Np

For $\mathrm{j}=1$ To Dim_y

Range("y_p_output").Cells(I, j) = Yy_p $(I, j)$

Next

Next

End Sub

Algorithm 1: The code of MSVM. 
because of low-quality core samples [14]. Alternatively, back analysis, associated with the "in situ" approach, has been widely used to determine the mechanical parameters of rock mass in rock engineering [15-20]. Zhang and Yin proposed a back analysis method which combined a neural network and a genetic algorithm to simultaneously identify the in situ stresses and elastic parameters [2]; however, this method did not consider the poroelastic effect. To overcome this difficulty, in this paper we extend our proposed displacement back analysis method to determine the in situ stress and mechanical parameters of a rock mass based on measured borehole pressure. The borehole pressure can be easily measured in the field with a pressure gauge installed inside the borehole [21]. Back analysis is implemented following an optimization strategy based on the multioutput support vector machine (MSVM) and artificial bee colony algorithm $(\mathrm{ABC})$ model, which is effective in multiple parameter identification [22].

The rest of this paper is organized as follows. The classic breakdown formula is presented in detail in Section 2. The formulation and procedure of back analysis based on borehole pressure are presented in detail in Section 3. In Section 4, a numerical example is used to verify the proposed method, and our conclusions are presented in Section 5.

\section{Hydraulic Breakdown Equations}

Hydraulic fracturing is a widely accepted technology used for determining in situ stress magnitude and direction. The principal stress $\sigma_{v}$ has a magnitude equal to the overburden pressure in the vertical direction. The smallest horizontal principal stress $\sigma_{h \min }$ is usually determined directly in the experiment from the shut-in pressure. The greatest horizontal principle stress $\sigma_{H \max }$ must be calculated using a breakdown formula derived from an appropriate hydraulic fracturing model. Hubbert and Willis proposed a classic breakdown formula (1) to calculate $\sigma_{H \max }$ for hydraulic fracturing in nonporous impermeable rocks [23], ignoring the pore pressure term.

$$
P_{b}=3 \sigma_{h \min }-\sigma_{H \max }+T,
$$

where $T$ is the rock tensile strength.

Equations (2) and (3) are the breakdown formulae of porous impermeable rocks and porous permeable rocks, respectively, including the pore pressure [24]:

$$
\begin{aligned}
& P_{b}=3 \sigma_{h \min }-\sigma_{H \max }+T-P_{p} \\
& P_{b}=\frac{3 \sigma_{h \min }-\sigma_{H \max }+T-\alpha((1-2 v) /(1-v)) P_{p}}{2-\alpha((1-2 v) /(1-v))},
\end{aligned}
$$

where $P_{b}$ is the breakdown pressure, $P_{p}$ is the pore pressure, $\alpha$ is the Biot poroelastic parameter, and $v$ is Poisson's ratio. Although (3) may best describe the conditions under which hydraulic fracturing is conducted from an open borehole, (2) is used in practice because of the difficulty of determining $\alpha$ and $v$. Schmitt and Zoback proposed a more generalized form for the equations of hydrofracture breakdown for porous impermeable rocks and porous permeable rocks [1]:

$$
\begin{aligned}
& P_{b}=3 \sigma_{h \min }-\sigma_{H \max }+T-\beta P_{p} \\
& P_{b}=\frac{3 \sigma_{h \min }-\sigma_{H \max }+T-\alpha((1-2 v) /(1-v)) P_{p}}{1+\beta-\alpha((1-2 v) /(1-v))},
\end{aligned}
$$

where $\beta$ is the poroelastic effect parameter.

\section{Back Analysis Model Based on Borehole Pressure}

The in situ stress can be estimated based on borehole pressure using the hydraulic breakdown equations (Section 2). However, these equations present some limitations in practice. Therefore, we propose a back analysis method that combines a numerical method and an intelligent computational method. A multioutput support vector machine (MSVM) is used to map the complex, nonlinear relationship between the in situ stress, elastic parameters, and borehole pressure. The numerical method provides the training samples for the MSVM. It is important to use an optimization method in back analysis. Here, we use the $\mathrm{ABC}$ algorithm to find the best-fit in situ stress and elastic parameters by comparing the measured pressure data and the MSVM predicted pressure.

3.1. Nonlinear Relationships between Pressure and Geomechanical Parameters. The relationship between the borehole pressure and geomechanical parameters can be derived by the MSVM. The basic idea of MSVM is to extend the single-output support vector machine to a multidimensional output case. Given a set of training samples $\left\{\left(X_{1}, Y_{1}\right),\left(X_{2}, Y_{2}\right), \ldots,\left(X_{N}, Y_{N}\right)\right\}, X_{i} \in R^{n}, Y_{i} \in R^{Q}$, the MSVM model can be built by solving the following optimization problem based on an iterative reweighted leastsquare algorithm [25].

$$
\begin{aligned}
L_{p}^{\prime}(W, b) & =\frac{1}{2} \sum_{j=1}^{Q}\left\|W_{j}\right\|^{2}+\frac{1}{2} \sum_{i=1}^{N} a_{i} u_{i}^{2}+\tau \\
a_{i} & = \begin{cases}0 & u_{i}^{t}<\varepsilon \\
2 C\left(u_{i}^{t}-\varepsilon\right) u_{i}^{t} & u_{i}^{t} \geq \varepsilon,\end{cases}
\end{aligned}
$$

where $N$ is the number of input, $Q$ is the number of output, $W$ is the weight, $b$ and $C$ are constants, $\tau$ is the sum of constant terms that do not depend on either $W$ or $b, \varepsilon$ is the tolerant error, and $t$ denotes the $t$ th iteration. A brief description and the MSVM algorithm can be found in the literature [22]. The MSVM model can be expressed as

$$
Y(X)=\sum_{k=1}^{n} \mathbf{W} k\left(X, X_{k}\right)+\mathbf{b} .
$$


Based on the above MSVM model, the nonlinear relationship between the borehole pressure and geomechanical parameters can be described as

$$
\begin{aligned}
\operatorname{MSVM}(\mathbf{X}): R^{n} & \longrightarrow R^{Q} \\
\mathbf{Y} & =\operatorname{MSVM}(\mathbf{X}),
\end{aligned}
$$

where $\mathbf{X}=\left(x_{1}, x_{2}, \ldots, x_{n}\right)$ is the $n$-dimensional vector of the identified parameter, for example, the in situ stress, Young's modulus, or Poisson's ratio. $\mathbf{Y}=\left(y_{1}, y_{2}, \ldots, y_{\mathrm{Q}}\right)$ is the $\mathrm{Q}^{-}$ dimensional vector of the borehole pressure.

To build the MSVM model, the necessary training or learning samples are constructed and the MSVM parameters are determined. The samples are constructed by numerical analysis which computes the corresponding borehole pressure for a given set of tentative determined parameters. The MSVM parameters have a strong influence on the performance of the MSVM. In this study, we determined these parameters using the formulation presented by Meza et al. [26].

3.2. Optimization Method. The back analysis ABC algorithm, developed by Karaboga [27], was adopted to search for the optimal geomechanical parameters of the rock mass. In the algorithm, the colony of artificial bees consists of three groups: employed bees, onlookers, and scouts. The ABC algorithm involves a cycle of four phases: the initialization phase, employed bees phase, onlooker bee phase, and scout bee phase.

In the initialization phase, the $\mathrm{ABC}$ generates a randomly distributed initial population of SN solutions and calculates the fitness of each solution.

$$
x(i, j)=x_{\min }^{j}+\operatorname{rand}(0,1)\left(x_{\max }^{j}-x_{\min }^{j}\right),
$$

where $x(i, j)$ is the candidate solution of the problem; $i=$ $1,2, \ldots, \mathrm{SN} / 2$ and $\mathrm{SN} / 2$ denotes the size of the population; $j=1,2, \ldots, D$ and $D$ is the dimension number of each solution; $\operatorname{rand}(0,1)$ is a random number between $[0,1] ; x_{\min }^{i}$ and $x_{\max }^{i}$ are the upper and lower bounds of each solution.

Once initialization is completed, the employed bees search for a solution and calculate the fitness value (see Section 3.3) in the employed bees phase. A candidate solution is produced according to the following equation:

$$
v(i, j)=x(i, j)+\varphi_{i j}(x(i, j)-x(k, j)),
$$

where $k$ is different from $i$ and is a randomly chosen index from $\{1,2, \ldots, \mathrm{SN} / 2\}, j$ is also an index randomly chosen from $\{1,2, \ldots, D\}$, and $\varphi_{i j}$ is a random number in the range $[-1,1]$ that controls the generation of food sources around $x(i, j)$ and represents the comparison of two food positions seen by a bee.

In the onlooker bee phase, the onlooker bees choose a solution based on the fitness value, determine which solution will be abandoned, and allocate its employed bees as scout bees. The probability of being selected for each fitness value can be expressed as

$$
p_{i}=\frac{\text { fitness }_{i}}{\sum_{n=1}^{\text {SN } \text { fitness }_{n}},}
$$

where fitness ${ }_{i}$ is the fitness value of the solution.
Finally, in the scout bee phase the scout bees randomly search for a new solution in the determined ranges. A solution that cannot be improved further through a predetermined number of cycles is assumed to be abandoned by the onlookers.

3.3. The Fitness Function. In order to find the optimal solution, it is necessary to build the fitness function for the $\mathrm{ABC}$ algorithm; that is,

$$
\text { fitness }=\sqrt{\frac{\|\operatorname{MSVM}(X)-Y\|^{2}}{Q}},
$$

where $\operatorname{MSVM}(X)$ is the predicted pressure using the MSVM model, $Y$ is the vector of the monitored pressure, and $Q$ is the number of monitored points.

3.4. Procedure of the MSVM-ABC Based Method. If the MSVM model can establish the nonlinear relation between the borehole pressures and determined parameters, the model can be used to predict the borehole pressures. Then, the $\mathrm{ABC}$ algorithm is utilized to find the optimal parameters through error minimization between the pressures predicted by the MSVM model and the measured pressures. The back analysis flowchart is shown in Figure 1 and the algorithm is described as follows.

Step 1. Determine the general information and data such as the unknown (determined by back analysis) and known parameters of the numerical model, the MSVM and ABC algorithm parameters, and the range of parameters to be determined.

Step 2. Generate the combination of determined parameters, calculate the borehole pressure for each combination, and then build the learning samples for MSVM.

Step 3. Based on the learning samples of Step 2, construct the MSVM model using the MSVM algorithm and activate the ABC algorithm.

Step 4. Search for the optimal determined parameters based on the monitored pressure.

\section{Validation and Application}

To verify the proposed method, a numerical example is adopted to determine the in situ stress and elastic mechanical parameters of the elastic rock. The numerical experiment is conducted based on 2D hydraulic fracturing model of water injection into a hypothetical deep formation. Further details of the physical and numerical model can be found in the literature published by Schmitt and Zoback [1].

The parameters to be determined are the maximum and minimum horizontal in situ stress $\sigma_{H \max }$ and $\sigma_{h \min }$, respectively, Young's modulus $E$, and Poisson's ratio $v$. The rock mass in all the zones is considered to be elastic. The mechanical parameters of the joints and the permeability 


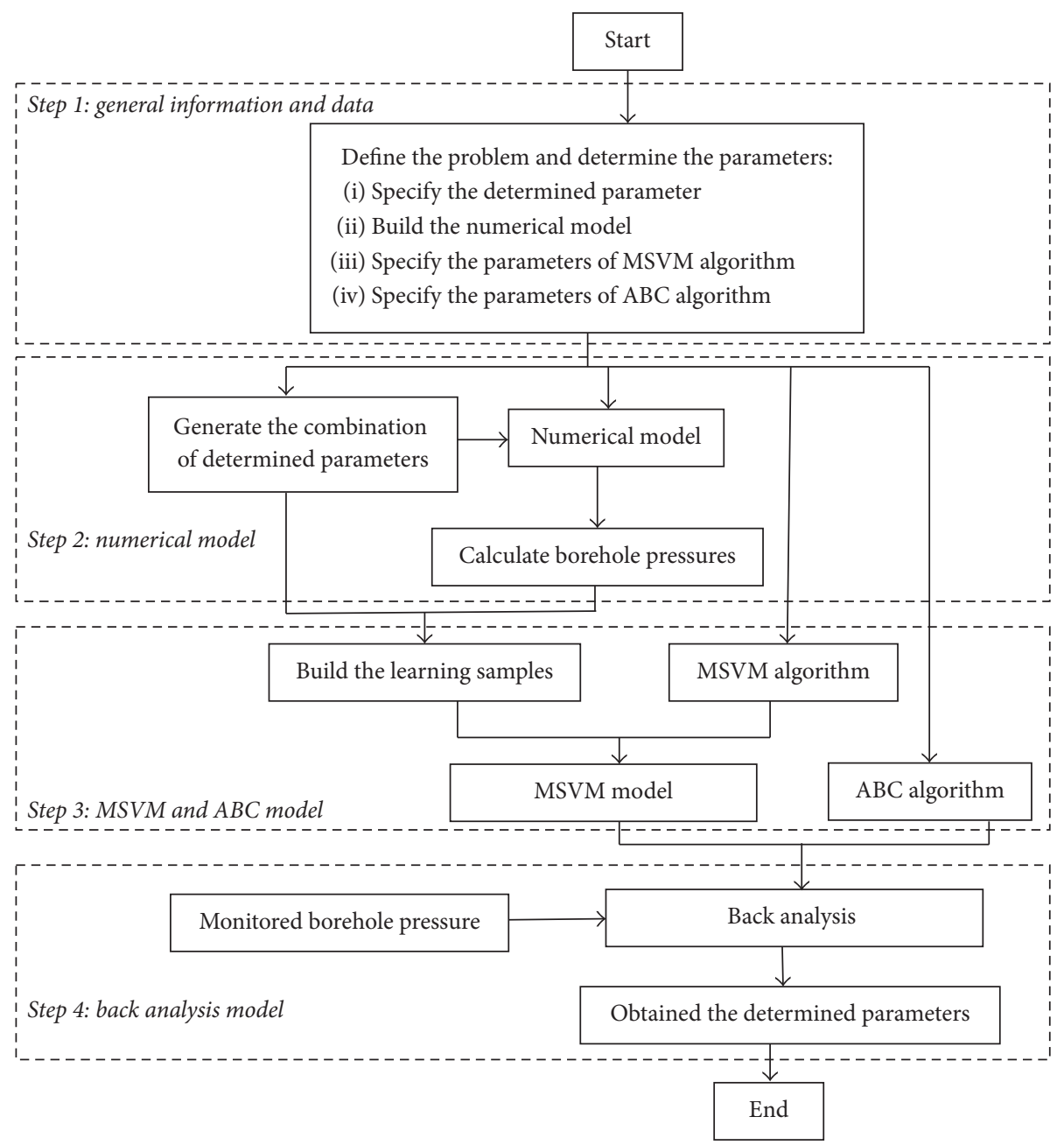

FIGURE 1: Flowchart of the back analysis process to obtain the rock parameters.

of the rock mass are known; the parameter values can be seen in the literature published by Schmitt and Zoback [1]. Thirty sets of training samples and ten testing samples derived in previous studies [1,2] were selected. Based on the MSVM algorithm, the MSVM code was written in Excel and VBA. The MSVM parameters and some of the weight $w_{i}$ and constant $b_{i}$ values and samples are shown in Figure 2. Good agreement between the measured data and the pressures estimated by the MSVM is shown in Figure 3, indicating the good performance of the MSVM model. Thus, the proposed model can accurately estimate the borehole pressures, replacing the existing numerical analysis method for calculating borehole pressures. The results also confirm that the MSVM model provides an accurate representation of the nonlinear relationship between the pressures and the determined parameters.

The ABC code is also written in Excel and VBA. The parameters of the $\mathrm{ABC}$ algorithm and the calculation results are shown in Figure 4. Based on the proposed method for determining the in situ stress and mechanical parameters of rock mass, the results are shown in Table 1 . we obtained the values of $\sigma_{H \max }, \sigma_{h \min }, E$, and $v$ as $24.46 \mathrm{MPa}, 14.33 \mathrm{MPa}$, $44.02 \mathrm{GPa}$, and 0.25 , respectively. The elastic mechanical parameters of the rock agree with the results calculated by the Genetic Algorithm-Neural Network (ANN-GA) [2]. A comparison of in situ stress values calculated using four different formulations is shown in Figure 5. $\sigma_{h \text { min }}$ agrees well with the value estimated by ANN-GA, (1), and (2). The relative error is only $1.07 \% . \sigma_{H \max }$ agrees well with the value estimated by (2), which considers the pore pressure, but differs considerably from the values calculated by (1) and ANN-GA which do not consider the poroelastic effects. The relative error is up to $31.8 \%$. Using (4), we obtain the upper and lower limits of the maximum horizontal in situ stress $\sigma_{H \max }(14.95-34.55 \mathrm{MPa})$. The value $24.46 \mathrm{MPa}$ is within this range. Thus, the proposed method can be used in back analysis as an alternative numerical analysis method, which considers the poroelastic effects and provides rational, high-precision results. Note that the proposed method can determine the maximum horizontal in situ stress without estimating the poroelastic coefficient, which is a difficult parameter to obtain. 
TABLE 1: Comparison of in situ stresses and mechanical parameters between MSVM model and other preexisted models.

\begin{tabular}{lcccc}
\hline Model & $\sigma_{H}(\mathrm{MPa})$ & $\sigma_{h}(\mathrm{MPa})$ & Young's modulus $E(\mathrm{GPa})$ & Poisson's ratio $v$ \\
\hline MSVM & 24.46 & 14.33 & 44.02 & 0.25 \\
ANN-GA $^{\#}$ & 35.83 & 14.968 & 39.92 & 0.26 \\
Eq. $(1)^{*}$ & 34.549 & 15.637 & & \\
Eq. $(2)^{*}$ & 24.749 & 15.637 & & \\
\hline
\end{tabular}

${ }^{\#}$ The model proposed by Zhang and Yin [2]. ${ }^{*}$ The model proposed by Hubbert and Willis [23].

\begin{tabular}{|c|c|c|c|c|c|c|c|c|c|c|c|c|}
\hline \multicolumn{13}{|c|}{$9 \quad$ Multioutput support vector machine } \\
\hline \multicolumn{3}{|c|}{ Parameters of MSVM } & \multicolumn{6}{|c|}{ Training samples } & \multicolumn{4}{|c|}{ Testing or predicting samples } \\
\hline$\sigma$ & $\varepsilon$ & C & Numbe & of san & les Dime & ion of inp & Dimens & of output & Number & f samples & & \\
\hline 5 & $1 E-05$ & 300 & & 0 & & 4 & & 4 & & & & \\
\hline Trai & ing sampl & & & & & & & & $\begin{array}{l}\text { Models of } N \\
\text { wi \& bi (The }\end{array}$ & $\begin{array}{l}\text { VM } \\
\text { rst row) }\end{array}$ & & \\
\hline & $\operatorname{pput}(x i)$ & & & & Output(y & & & & 25.51749 & 41.53803 & 25.30404 & 22.62262 \\
\hline 1 & 44.9 & 34.1 & 40.0 & 0.2 & 39.778 & 66.733 & 40.377 & 37.482 & 32.69383 & 61.6205 & 28.92746 & 36.87203 \\
\hline 2 & 43.8 & 30.9 & 42.0 & 0.3 & 35.882 & 60.069 & 37.09 & 32.905 & -5.799298 & -0.497959 & 2.342793 & -6.83015 \\
\hline 3 & 43.2 & 15.7 & 25.0 & 0.3 & 19.425 & 25.968 & 18.394 & 16.293 & -2.643523 & -11.87645 & -8.24627 & -8.16457 \\
\hline 4 & 42.9 & 20.0 & 30.0 & 0.2 & 21.183 & 30.267 & 22.859 & 20.486 & -26.79601 & -28.7827 & -8.93134 & -5.26611 \\
\hline 5 & 42.3 & 33.0 & 40.0 & 0.2 & 37.403 & 61.538 & 37.959 & 34.59 & -7.965503 & -24.82346 & -13.728 & -8.95032 \\
\hline 6 & 41.9 & 28.5 & 42.0 & 0.3 & 33.423 & 54.845 & 34.099 & 30.028 & -10.14168 & 5.245473 & -15.5702 & -11.6237 \\
\hline 7 & 41.0 & 17.8 & 26.0 & 0.3 & 21.578 & 27.741 & 20.437 & 18.33 & 14.51593 & -10.42965 & 2.294206 & 4.102865 \\
\hline 8 & 40.4 & 31.3 & 47.0 & 0.3 & 37.074 & 60.791 & 37.452 & 33.623 & 13.77002 & 10.75531 & 13.80466 & 12.93566 \\
\hline 9 & 39.8 & 27.0 & 38.0 & 0.2 & 32.056 & 43.779 & 33.969 & 28.521 & 2.65743 & -51.59696 & 23.6693 & 0.200652 \\
\hline 10 & 39.2 & 11.3 & 28.0 & 0.2 & 14.387 & 21.38 & 13.928 & 11.916 & -15.18197 & -8.023748 & -11.0173 & -10.7767 \\
\hline 11 & 38.9 & 29.9 & 41.0 & 0.3 & 35.089 & 57.713 & 35.694 & 31.699 & 2.148607 & 37.66816 & 0.857885 & 4.119908 \\
\hline 12 & 38.1 & 18.9 & 35.0 & 0.3 & 23.467 & 30.347 & 22.057 & 19.47 & 7.290676 & -2.550754 & -4.21743 & -2.08841 \\
\hline 13 & 37.6 & 27.4 & 27.0 & 0.3 & 31.439 & 51.838 & 32.584 & 28.979 & 9.948569 & 50.389 & 14.00926 & 11.58154 \\
\hline 14 & 36.5 & 14.9 & 37.0 & 0.2 & 19.223 & 27.261 & 18.048 & 15.485 & 0.180288 & 14.13271 & -0.47812 & -2.10495 \\
\hline 15 & 35.5 & 25.1 & 39.0 & 0.2 & 30.255 & 39.013 & 28.688 & 26.052 & -3.420387 & -48.26779 & -22.4071 & -7.36326 \\
\hline 16 & 34.6 & 12.8 & 24.0 & 0.3 & 16.305 & 23.295 & 15.414 & 13.331 & -3.60225 & 1.880641 & -2.63221 & -3.7458 \\
\hline 17 & 33.8 & 28.9 & 42.0 & 0.3 & 34.409 & 55.727 & 34.523 & 30.596 & 9.328942 & 61.70773 & 16.13344 & 9.398126 \\
\hline 18 & 33.2 & 17.9 & 32.0 & 0.3 & 22.06 & 28.912 & 20.846 & 18.474 & 4.171029 & 8.203456 & 4.833736 & 4.764868 \\
\hline 19 & 32.5 & 10.3 & 36.0 & 0.2 & 13.789 & 20.18 & 13.122 & 10.948 & -16.877 & -20.59279 & -12.9272 & -11.6762 \\
\hline 20 & 31.5 & 24.9 & 21.0 & 0.2 & 28.983 & 45.886 & 29.211 & 25.937 & 12.27877 & 38.88137 & 15.94925 & 12.30997 \\
\hline 21 & 31.1 & 16.9 & 24.0 & 0.3 & 20.342 & 26.571 & 19.426 & 17.392 & -1.505729 & -21.8008 & -2.46657 & 0.202625 \\
\hline 22 & 30.5 & 22.7 & 35.0 & 0.3 & 27.216 & 35.282 & 25.95 & 23.289 & -1.505308 & 3.553947 & -0.44801 & -0.55972 \\
\hline 23 & 29.5 & 25.1 & 40.0 & 0.2 & 29.886 & 39.043 & 28.714 & 26.014 & 1.008502 & -27.74127 & 0.52993 & 3.700371 \\
\hline 24 & 28.4 & 13.6 & 28.0 & 0.2 & 17.67 & 24.647 & 16.346 & 14.127 & 6.005568 & 17.7538 & 1.352429 & -0.47782 \\
\hline 25 & 27.8 & 20.2 & 32.0 & 0.2 & 24.602 & 30.77 & 23.131 & 20.661 & 0.912869 & -3.943866 & 0.386886 & 0.365483 \\
\hline 26 & 27.2 & 15.8 & 26.0 & 0.3 & 19.189 & 26.153 & 18.522 & 16.371 & -6.679902 & 8.441547 & 3.515295 & 2.837635 \\
\hline 27 & 26.9 & 13.1 & 43.0 & 0.3 & 17.573 & 24.725 & 16.366 & 13.71 & -13.40561 & -17.60743 & -13.6856 & -14.2492 \\
\hline 28 & 26.3 & 20.6 & 27.0 & 0.3 & 24.947 & 30.101 & 23.283 & 21.048 & 8.177915 & -25.86171 & 0.189852 & 2.768714 \\
\hline 29 & 25.7 & 21.3 & 38.0 & 0.2 & 26.112 & 33.84 & 24.708 & 21.888 & 6.515285 & 9.419643 & 6.692563 & 4.489202 \\
\hline 30 & 25.1 & 11.1 & 21.0 & 0.3 & 14.721 & 20.638 & 13.348 & 11.579 & -16.08006 & -25.25597 & -18.7337 & -16.7728 \\
\hline
\end{tabular}

Figure 2: Parameters and model of MSVM in the Excel VBA platform. 


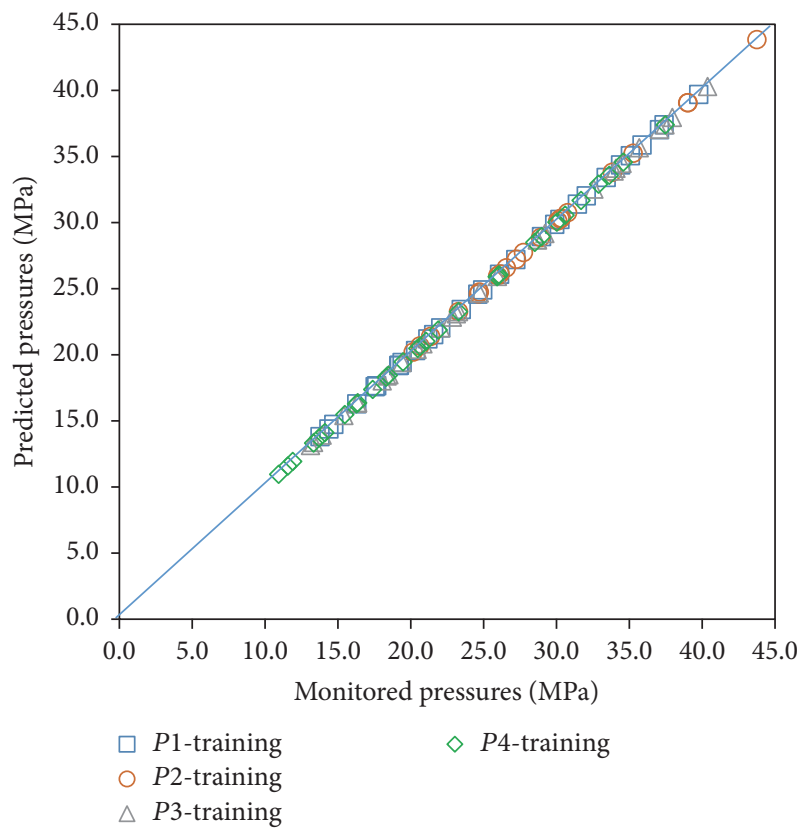

(a)

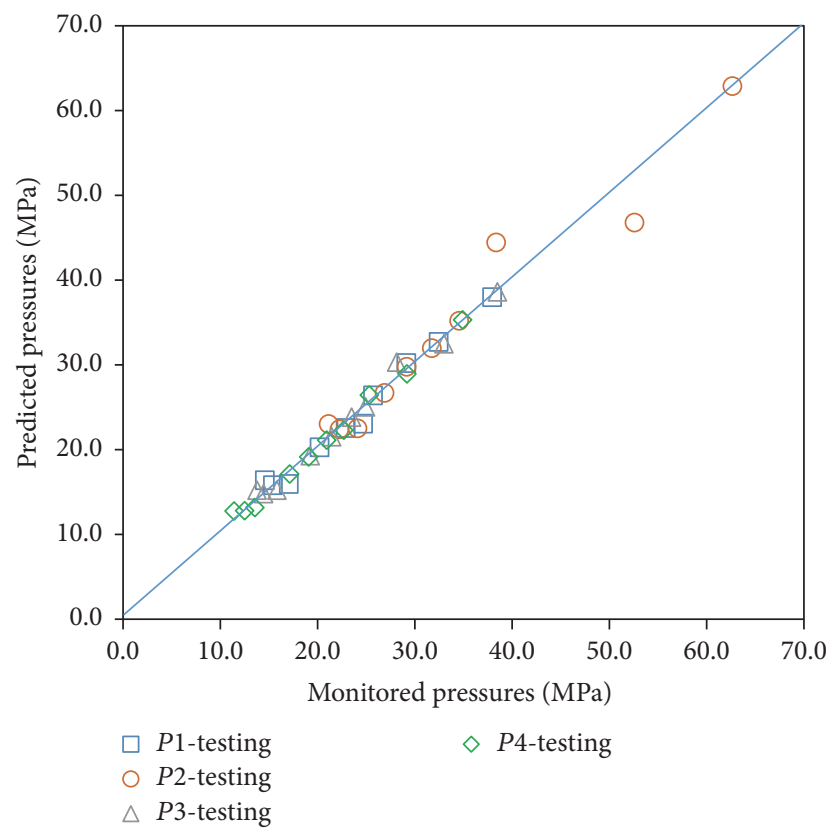

(b)

FIgURE 3: Comparison of pressure data estimated by MSVM and borehole measured data.

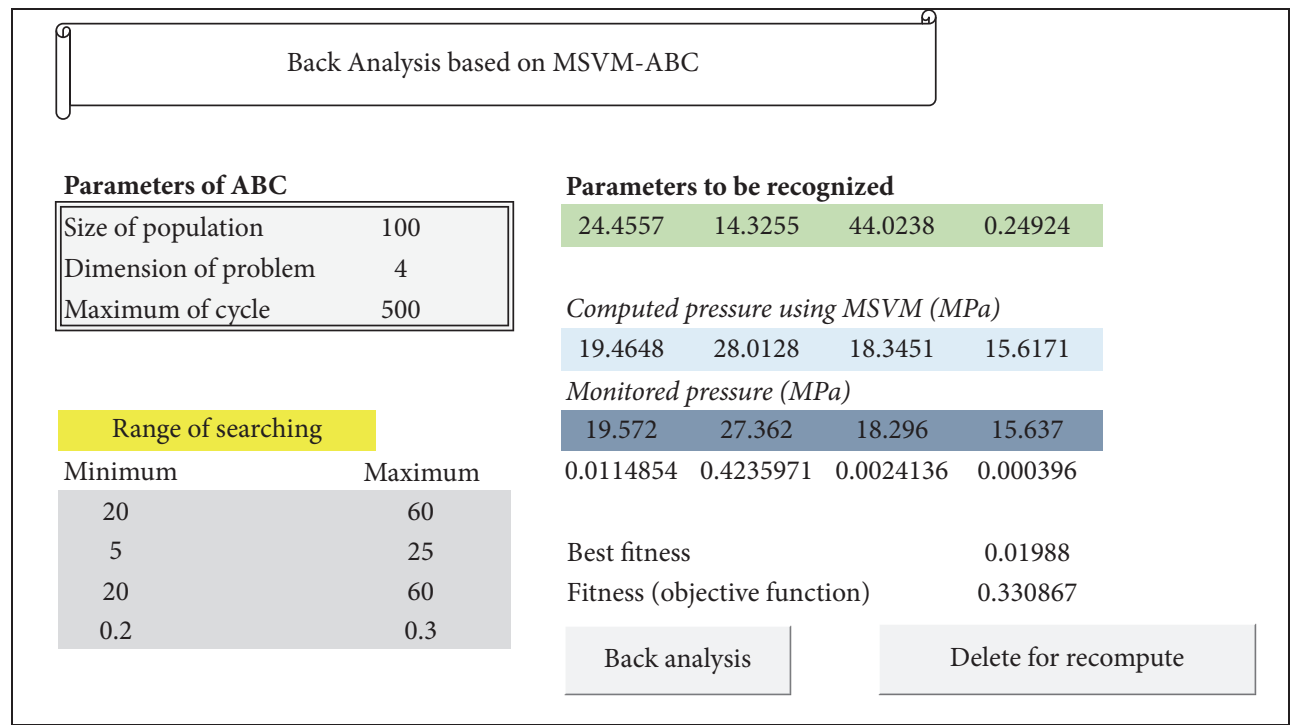

Figure 4: MSVM-ABC-based back analysis, its parameters, and results in the Excel VBA platform.

Moreover, there are four borehole pressures, namely, formation breakdown pressure (FBP) $P 1$, fracture propagation pressure (FPP) $P 2$, instantaneous shut-in pressure (ISIP) $P 3$, and leak-off pressure (LOP) P4. A comparison of back analysis on borehole pressures obtained by three different methods is presented in Figure 6. The borehole pressure calculated by the proposed MSVM method is very close to the measured pressure. The relative error is less than 3\%. On the other hand, the convergence processes of the algorithm and fitness variations are shown in Figures 7 and 8. Initially, the data was distributed randomly in the searching space
(Figure 8) and then converged to the solution of the problem in the 500th generation. This indicates that the proposed method can determine both the in situ stress and elastic mechanical parameters of the elastic rock with excellent converging performance.

\section{Conclusions}

In this paper, a new borehole pressure-based back analysis approach to determine the stress and mechanical parameters of rock mass is proposed. The method combines a coupling 


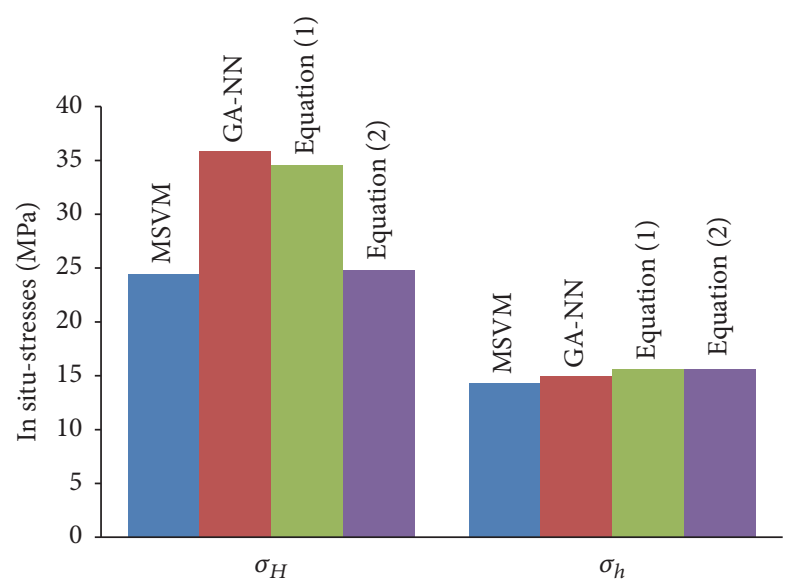

Figure 5: Comparison of recognized in situ stress using different models ( $\sigma_{H}, \sigma_{h}$ are the maximum and minimum in situ stress).

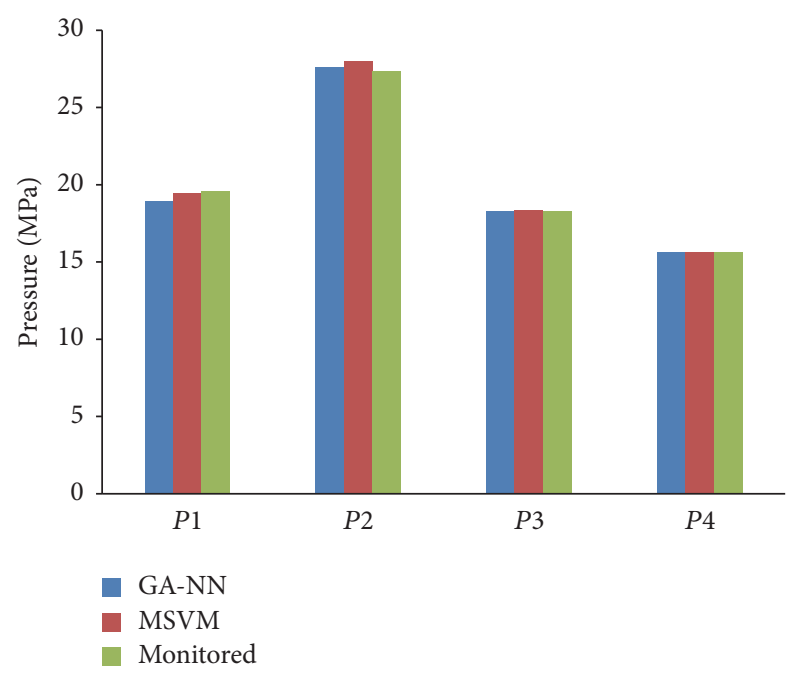

Figure 6: Comparison of borehole pressures obtained by different prediction methods and monitored data.

numerical model of hydraulic fracturing and a computational intelligent method. The method is applied to a numerical example to successfully determine both the in situ stress and mechanical parameters of a rock mass. In this approach, the MSVM is adopted to represent the nonlinear relationship between the borehole pressure and mechanical parameters of the rock mass, proving more efficient than existing numerical models. The ABC algorithm is used to search for the optimal parameters in the search space. The proposed approach is implemented in Excel with VBA.

In the classic breakdown formula, it is difficult in practice to determine the maximum horizontal in situ stress while considering the poroelastic coefficient. The proposed back analysis method can predict the maximum horizontal in situ stress based on the borehole pressures without the need to obtain the poroelastic coefficient. Thus, it is a more practical method for determining the in situ stress from hydraulic fracturing. The proposed method is practical and accurate and can be conveniently applied to simultaneously determine

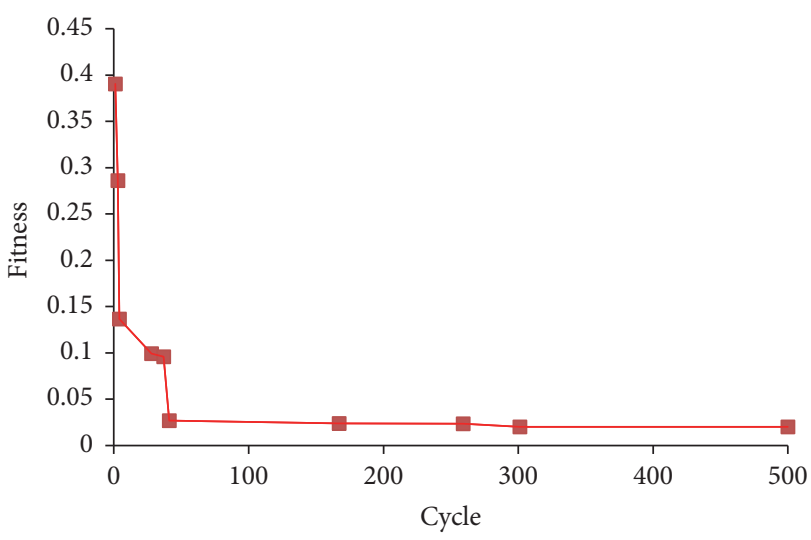

FIgURE 7: Fitness variation with increased cycles in the $A B C$ analysis.

the in situ stress and mechanical parameters of rock from hydraulic fracturing.

\section{Symbols}

$\sigma_{v}: \quad$ Principal stress in $y$ direction

$\sigma_{H \max }: \quad$ The greatest horizontal principle stress

$\sigma_{h \min }: \quad$ The smallest horizontal principal stress

$v: \quad$ Poisson's ratio

$\beta$ : $\quad$ Poroelastic effect parameter

$W: \quad$ The weight vector

$\operatorname{MSVM}(X)$ : The predicted pressure using the MSVM model

C: $\quad$ Hyper parameter that determines trade-off between the regularization and the error reduction term

$\varepsilon: \quad$ Tolerant error

Q: $\quad$ Number of output

$\varphi_{i j}: \quad$ A random number in the range $[-1,1]$

$b$ : A constant for classification threshold

$P_{b}: \quad$ Breakdown pressure

$P_{p}: \quad$ Pore pressure

$E: \quad$ Young's modulus

$\alpha: \quad$ Biot poroelastic parameter

$T: \quad$ Rock tensile strength

$N$ : Number of input

$\tau$ : $\quad$ Sum of constant terms that do not depend on either $W$ or $b$

$\operatorname{rand}(0,1):$ A random number between $[0,1]$

fitness: Fitness value of the solution.

\section{Conflicts of Interest}

The authors declare that they have no conflicts of interest.

\section{Acknowledgments}

The authors gratefully acknowledge the National Natural Science Foundation of China (Grant no. 41372315), the State Key Research Development Program of China (Grant 


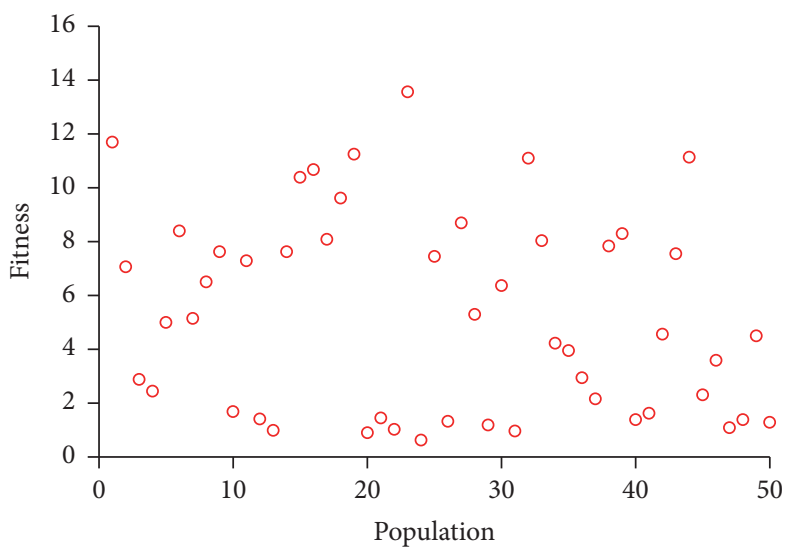

- Initial generation

(a)

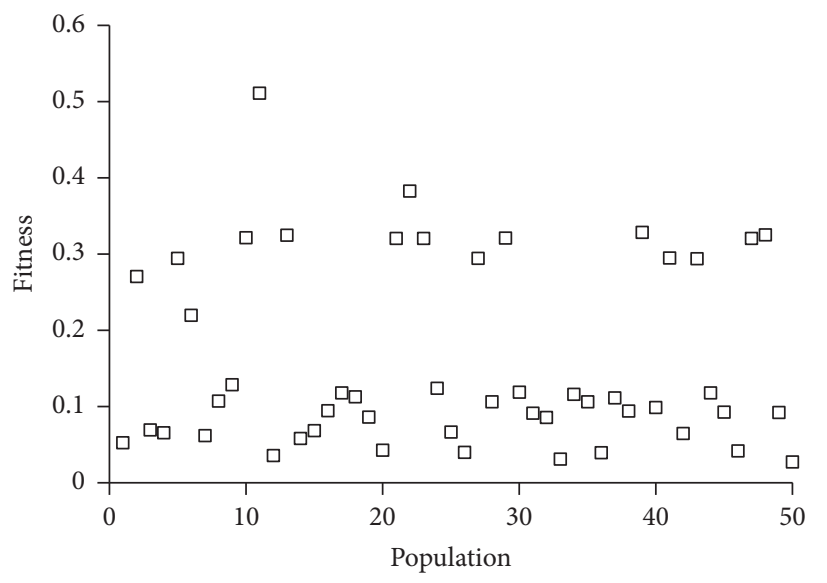

$\square$ 200th generation

(c)

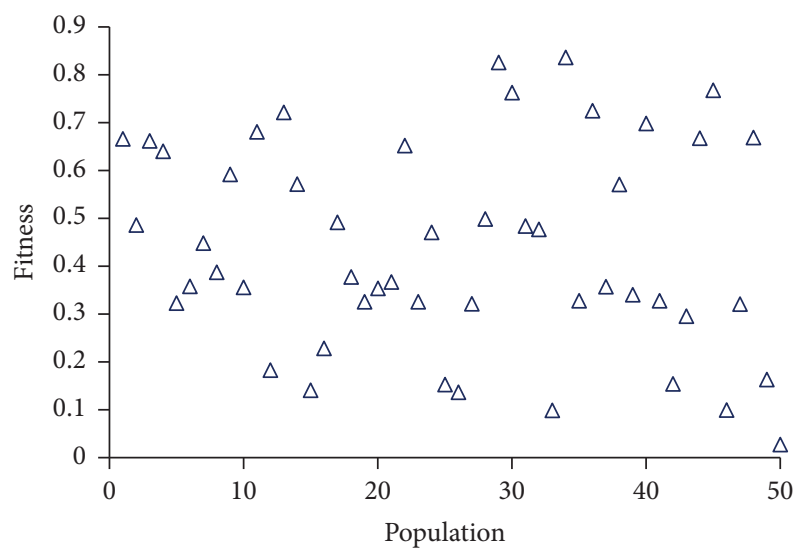

$\triangle 50$ th Generation

(b)

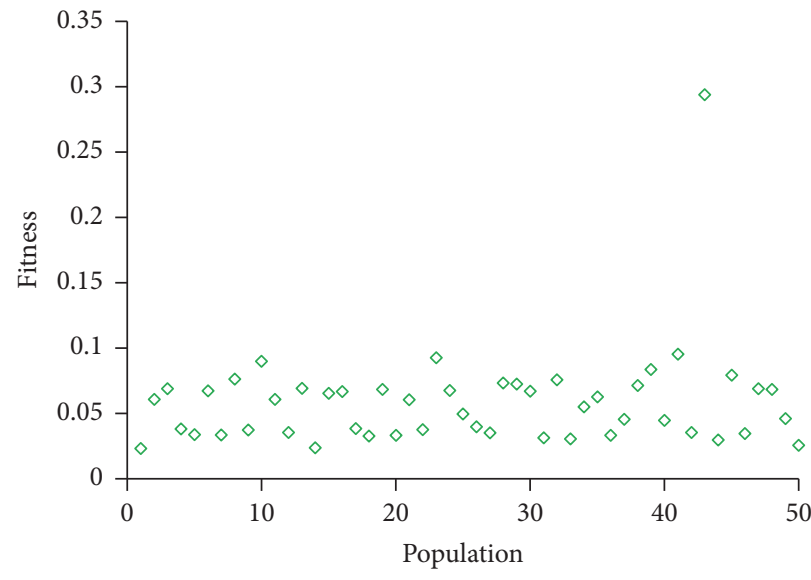

$\diamond 500$ th generation

(d)

FIGURE 8: Fitness distribution in the searching space at different cyclic stages.

no. 2016YFC0600702), and Innovative Research Team (in Science and Technology) in University of Henan Province (no. 15IRTSTHN029).

\section{References}

[1] D. R. Schmitt and M. D. Zoback, "Poroelastic effects in the determination of the maximum horizontal principal stress in hydraulic fracturing tests-A proposed breakdown equation employing a modified effective stress relation for tensile failure," International Journal of Rock Mechanics and Mining Sciences and, vol. 26, no. 6, pp. 499-506, 1989.

[2] S. Zhang and S. Yin, "Determination of in situ stresses and elastic parameters from hydraulic fracturing tests by geomechanics modeling and soft computing," Journal of Petroleum Science and Engineering, vol. 124, pp. 484-492, 2014.

[3] Z. Fang and A. Khaksar, "Complexity of minifrac tests and implications for in-situ horizontal stresses in coalbed methane reservoirs," in Proceedings of the International Petroleum Technology Conference, Bangkok, Thailand, 2011.

[4] B. C. Haimson and C. Fairhurst, "In-situ stress determination at great depth by means of hydraulic fracturing," in Proceedings of the 11th U.S. Symposiumon RockMechanics (USRMS), pp. 559584, Berkeley, CA, USA, 1969.

[5] B. C. Haimson, "The hydrofracturing stress measuring method and recent field results," International Journal of Rock Mechanics and Mining Sciences and, vol. 15, no. 4, pp. 167-178, 1978.

[6] B. C. Haimson, "The hydraulic fracturing method of stress measurement: theory and practice," in Comprehensive Rock Engineering, J. A. Hudson, Ed., vol. 3, pp. 395-412, Pergamon Press, Oxford, 1993.

[7] J. W. Puller, K. W. Mills, R. G. Jeffrey, and R. J. Walker, "In-situ stress measurements and stress change monitoring to monitor overburden caving behaviour and hydraulic fracture pre-conditioning," International Journal of Mining Science and Technology, vol. 26, no. 1, pp. 103-110, 2016.

[8] A. J. White, M. O. Traugott, and R. E. Swarbrick, "The use of leak-off tests as means of predicting minimum in-situ stress," Petroleum Geoscience, vol. 8, no. 2, pp. 189-193, 2002.

[9] H. Xu, S. Sang, J. Yang et al., "In-situ stress measurements by hydraulic fracturing and its implication on coalbed methane development in Western Guizhou, SW China," Journal of Unconventional Oil and Gas Resources, vol. 15, pp. 1-10, 2016. 
[10] B. Haimson and C. Fairhurst, "Initiation and extension of hydraulic fractures in rocks," Society of Petroleum Engineers Journal, vol. 7, no. 03, pp. 310-318, 2013.

[11] W. Medlin and L. Masse, "Laboratory investigation of fracture initiation pressure and orientation," Society of Petroleum Engineers Journal, vol. 19, no. 02, pp. 129-144, 2013.

[12] J. R. Rice and M. P. Cleary, "Some basic stress diffusion solutions for fluid saturated elastic porous media with compressible constituents," Reviews of Geophysics, vol. 14, no. 2, pp. 227-241, 1976.

[13] A. E. Scheidegger, "Stresses in the Earth's crust as determined from hydraulic fracturing data," Geol. Bauwes, pp. 45-53, 1962.

[14] I. Ocak and S. E. Seker, "Estimation of elastic modulus of intact rocks by artificial neural network," Rock Mechanics and Rock Engineering, vol. 45, no. 6, pp. 1047-1054, 2012.

[15] X. T. Feng, H. B. Zhao, and S. J. Li, "A new displacement back analysis to identify mechanical geo-material parameters based on hybrid intelligent methodology," Int. J. Num. Anal. Methods Geomech, pp. 28-1141, 2004.

[16] G. Gioda and L. Jurina, "Numerical identification of soil structure interaction pressures," International Journal for Numerical and Analytical Methods in Geomechanics, pp. 33-56, 1981.

[17] S. Li, H. Zhao, Z. Ru, and Q. Sun, "Probabilistic back analysis based on Bayesian and multi-output support vector machine for a high cut rock slope," Engineering Geology, vol. 203, pp. 178-190, 2016.

[18] P. Oreste, "Back-analysis techniques for the improvement of the understanding of rock in underground constructions," Tunnelling and Underground Space Technology, vol. 20, no. 1, pp. 7-21, 2005.

[19] B. Pichler, R. Lackner, and H. A. Mang, "Back analysis of model parameters in geotechnical engineering by means of soft computing," International Journal for Numerical Methods in Engineering, vol. 57, no. 14, pp. 1943-1978, 2003.

[20] S. Sakurai and K. Takeuchi, "Back analysis of measured displacements of tunnels," Rock Mechanics and Rock Engineering, vol. 16, no. 3, pp. 173-180, 1983.

[21] G. D. Cooper, S. G. Nelson, and M. D. Schopper, "Improving fracturing design through the use of a on-site computer system," in Proceedings of the SPE12063 presented at the 1983 SPE Annual Technical Conference Exhibition, SanFrancisco, CA, 1983.

[22] H. Zhao and S. Yin, "Inverse analysis of geomechanical parameters by the artificial bee colony algorithm and multi-output support vector machine," Inverse Problems in Science and Engineering, vol. 24, no. 7, pp. 1266-1281, 2016.

[23] M. K. Hubbert and D. G. Willis, "Mechanics of hydraulic fracturing," Trans. AIME, vol. 210, pp. 153-163, 1957.

[24] E. Detournay and H. D. Cheng, "Poroelastic response of a borehole in a non-hydrostatic stress field," Int. J. Rock Mech. Min. Sci. Geomech. Abstr, pp. 171-182, 1988.

[25] D. Tuia, J. Verrelst, L. Alonso, F. Perez-Cruz, and G. CampsValls, "Multioutput support vector regression for remote sensing biophysical parameter estimation," IEEE Geoscience and Remote Sensing Letters, vol. 8, no. 4, pp. 804-808, 2011.

[26] A. M. Á. Meza, G. D. Santacoloma, C. D. Acosta Medina, and G. C. Domínguez, "Parameter selection in least squares-support vector machines regression oriented, using generalized crossvalidation," DYNA (Colombia), vol. 79, no. 171, pp. 23-30, 2012.

[27] D. Karaboga, "An idea based on honey bee swarm for numerical optimization,” Technical Report-TR06, Erciyes University, Engineering Faculty, Computer Engineering Department, 2005. 

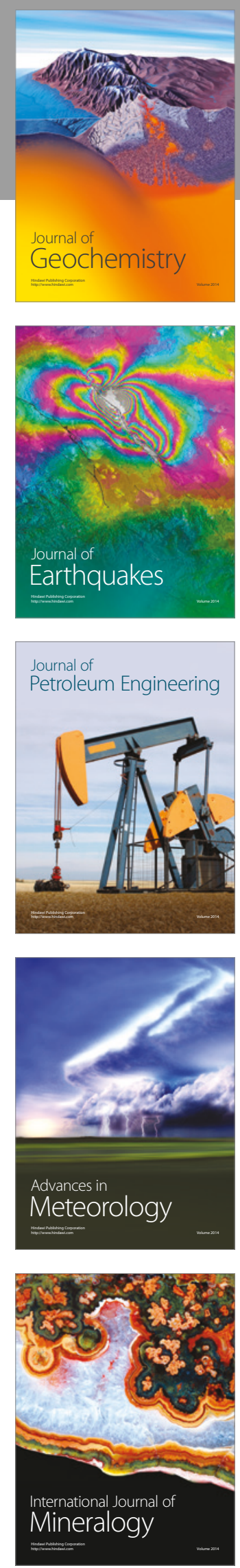
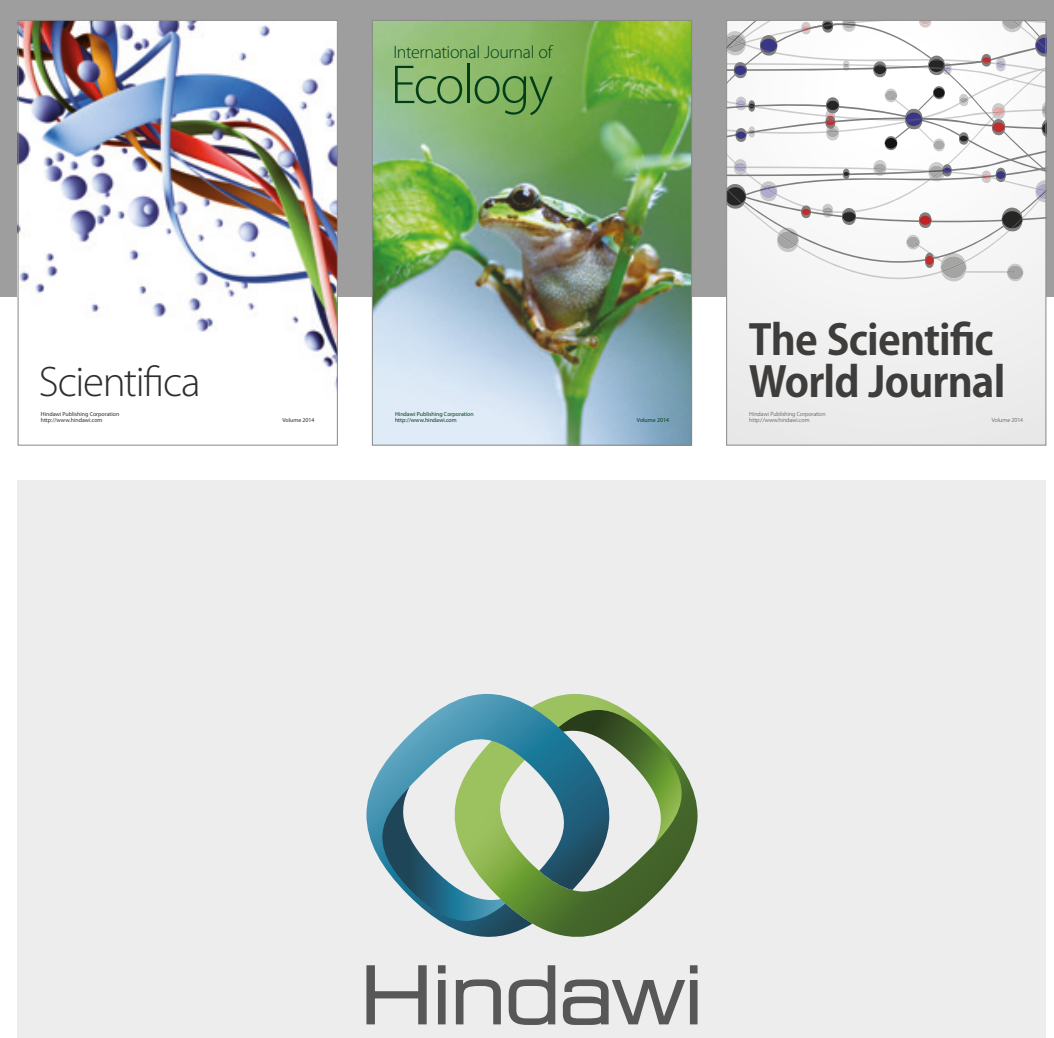

Submit your manuscripts at

https://www.hindawi.com
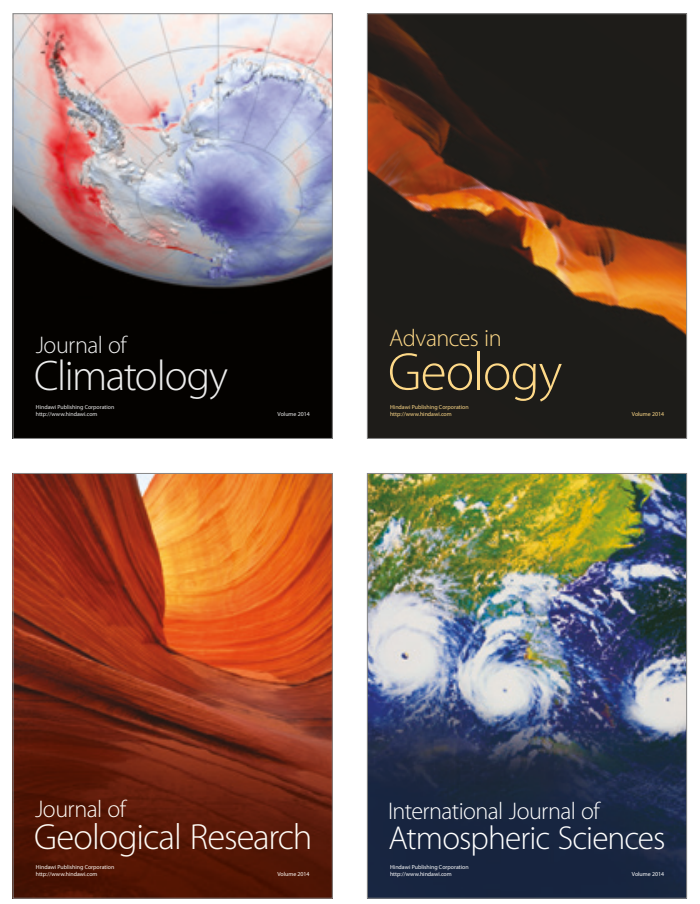

The Scientific

World Journal
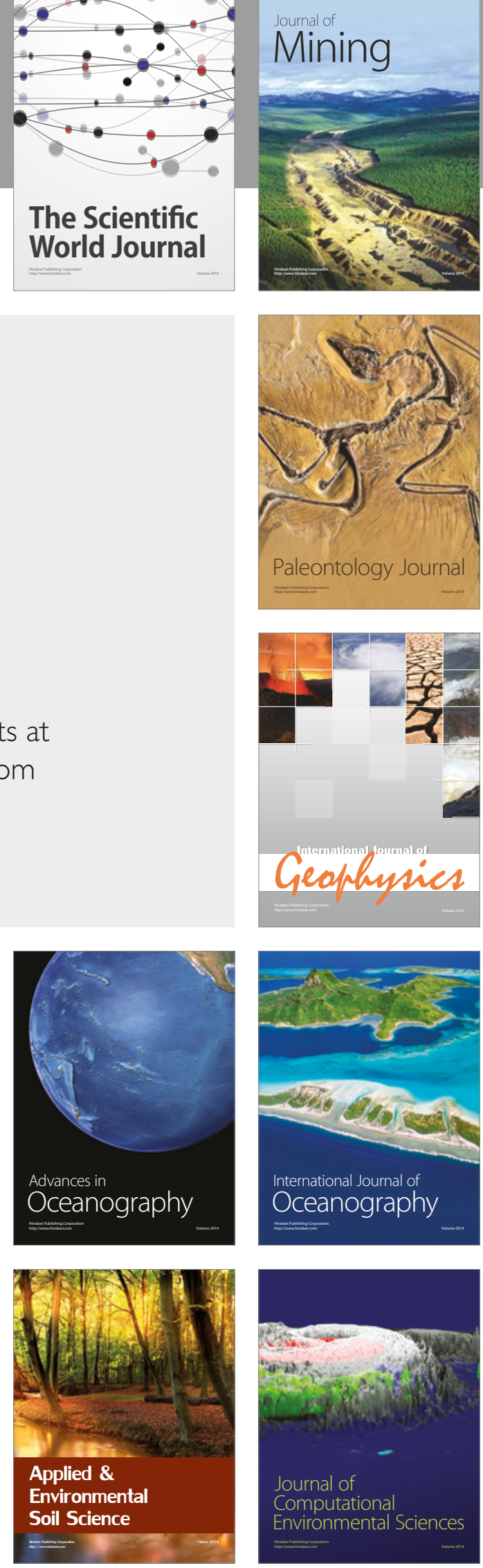